\title{
Analyzing the Effects of Team Member's Solidarity Behavior in the Team Negotiation Environment
}

\author{
Jian Wang ${ }^{1, a}$, Jingqiu Gong ${ }^{1, b}$ \\ ${ }^{1}$ Systems Engineering Institute, School of Automation, Huazhong University of Science and \\ Technology, Wuhan, Hubei, P.R. China
}

àw0826_can@mail.hust.edu.cn, b949473800@qq.com

Keywords: team negotiation; solidarity behavior; conflict; concession strategy; agent-based simulation.

\begin{abstract}
Nowadays, many researches have concentrated on team negotiation in various negotiation environments. Although the effectiveness of team negotiation has been proven, the effects of team member's solidarity behavior on the process and outcome of negotiation have not been explored yet. In this paper, the team negotiation problem and solidarity behavior pattern are modeled based on the team negotiation environment. The solidarity behavior is reflected in making a contribution to others. Moreover, the intra-team concession strategy would be considered in the negotiation process when the interest conflicts occur. In addition, an agent-based simulation approach is introduced to construct the experimental negotiation environment. The experiment results indicate that the concession strategy can be employed for dealing with conflicts efficiently. With respect to the concession strategy, there are two ways for selecting beneficiary to accept the contribution: The deviation-maximum way and the increment-maximum way. The two ways may result in different negotiation performance when the team members have varied utility standards. In summary, the positive significance of solidarity characteristic is verified, and various factors need to be comprehensively taken into account to reach an agreement efficiently in the negotiation process.
\end{abstract}

\section{Introduction}

In recent years, the application of team negotiation has become increasingly prevalent. Team negotiation, it can be regarded as a joint decision-making process to solve social conflicts. Take the electronic business for instance, because of the mechanism of Credit Based Group Negotiation, the buyers and the sellers can efficiently bargain and achieve more benefits [1].

According to current researches, there are mainly two key points in team negotiation: team characteristics and negotiation mechanism. The team characteristics include power distance, cultural diversity and humor factor $[2,3,4]$. These researches mainly focus on team members' behavior related to the negotiation performance. In addition, the negotiation mechanism is also important for team negotiation. It is mainly made up by the negotiation strategies carried out by the team members and the negotiation protocols used for interacting with the opponent $[2,5]$.

Although the effectiveness of team negotiation has been proven, the interest conflicts would have a detrimental effect on the negotiation process or outcome $[6,7]$. As is well known, the group members act not only for themselves but also are motivated by the team interest [8]. For the sake of the team's objective, many individuals tend to make concessions or sacrifice their own interests to benefit others. Therefore, the solidarity behavior emerged.

The solidarity factor can be viewed as an implicit agreement that motivates the individuals to make contributions in the team. The team members are inclined to reach out to others who are in relatively worse states [9]. In these cases, solidarity behavior promote the individuals to maximize teammates' incomes and attain the negotiation goal. In general, the members have different preferences and value judgments, which particularly lead to the differences in utility $[5,10]$. Personal solidarity factor will also influence the utility functions, the distribution of interests [11, 12], the emotional state to contribute [13], as well as the effort to reach an agreement. Therefore, how the solidarity factor 
affects the negotiation process, thus enhancing the overall performance in the team is an interesting problem.

In addition, with the development of artificial intelligence, agent-based simulation approach has been widely adopted for team negotiation. This approach is not only able to aggregate individuals' preferences and utilities [5], but also it is adapted to the simulation of interacting with negotiating parties [1]. Other than team member's behavior, it is likewise appropriate for positioning the intrateam strategy in different environmental scenarios. In this paper, the agent-based simulation approach is adopted to construct the simulation environment of team negotiation, and a heuristic technique that the negotiation team forms the counteroffer on the basis of opponent' offer is employed for reaching a satisfactory agreement.

In this electronic shopping environment Ref. [1] mentions that buyer agents may have different goods requirements. In order to achieve respective requirements, different buyer agents with the same goods demand will form coalition and negotiate with the trading seller. In our paper, each party is composed of three departments such as research department, transportation department and quality department. Different functional departments have different requirements and concerns. Additionally, Ref. [14] mentions that in the multi-agent negotiation scenario, the task is always decomposed into several sub-tasks because the single agent is lacking of professional knowledge and ability to implement the whole task. Similarly, the task of team negotiation in my paper is to reach an agreement on product purchase and the task is deposed into three sub-tasks. Each department has its own requirements and needs to achieve respective sub-task. For the concurrent negotiation framework, each department is able to negotiate with its counterparty independently.

The main purpose of this paper is to discuss the effects of negotiation mechanism caused by the member's solidarity behavior in the team negotiation environment and explore how the negotiation goal can be reached in a more efficient way. The paper is organized as follows. Firstly, the problem of team negotiation and its formal model are described. Secondly, the agent-based simulation approach employed for the team negotiation is showed. Thirdly, the simulation experiments are conducted and the results are analyzed. At last, some conclusions and directions for future work are presented.

\section{Problem statement}

Team negotiation background. In this section, the main problem in team negotiation will be described. In the commercial negotiation environment, the team members may make concessions to deal with the interest conflicts in two-party negotiation and then attain the negotiation goal $[1,15,16]$. In my paper, the overall negotiation goal for the two parties is to achieve satisfactory benefits from product purchase $[1,16]$. The overall negotiation task is deposed into three sub-tasks. Three different functional departments for each party such as research department, transportation department and quality department will perform their respective duties independently and concurrently. The research department team in the buying party negotiates with the research department team of the selling party by considering the attributes such as material costs, productive technology and access to technicians $[17,18,19]$. Likewise, the transportation departments in two parties focus on the attributes such as transportation mode, environmental level and product security [20]. The quality departments in two parties consider the attributes such as solution selection, equipment requirement and data reliability $[21,22,23]$. Each of the team members have different preferences and utility functions, and the goal of the each department is to reach an agreement on the related attributes which are closely associated with their department. When all of the functional department teams reach an agreement on their related attributes respectively, the overall negotiation task will be achieved.

Solidarity behavior in the negotiation process. According to actual situations, the interest conflicts are likely to appear in negotiation interaction when the actual benefit (utility) caused by the opponent's offer can not meet utility standard for some team members within the team. If so, it provides the needs 
for concession within the team to complete negotiation sub-tasks. Endogenous solidarity factor exactly shows some ways to adjust and balance team members' benefits. The detail is shown in the Fig. 1 below.

As shown in the Fig.1, the solidarity action is applied in the interaction process where the selling party negotiates with the buying party. Three different functional departments of each party will perform their respective duties respectively. For the study of negotiation mechanism under the influence of solidarity characteristic, we take one of departments of each party for instance to simulate the negotiation process and explore the effects of solidarity on negotiation performance in the rest of the paper. In detail, for the research department teams in two parties, the offer proposed by the opponent may provides relative less benefit and can not meet utility standard for some team members. According to the beneficiary's preference on related attributes such as material costs, productive technology and the access to technicians, the team members who possess solidarity characteristic make concessions to adjust attributes' value and ensure that all team members meet their interest requirements. In a word, detracting from their own utilities to make up for the others' benefits within the team is exactly solidarity behavior. After the concession, the research department team proposes the counteroffer to the opponent's research department team and renegotiates in another negotiation round if necessary.

Formal problem definition. In order to describe the team negotiation process, some basic variables and parameters need to be quantified. Firstly, the different preferences and utility functions for team members are defined. Secondly, the concession strategy related to solidarity behavior is described. At last, the negotiation goal for the negotiation team needs to be quantified.

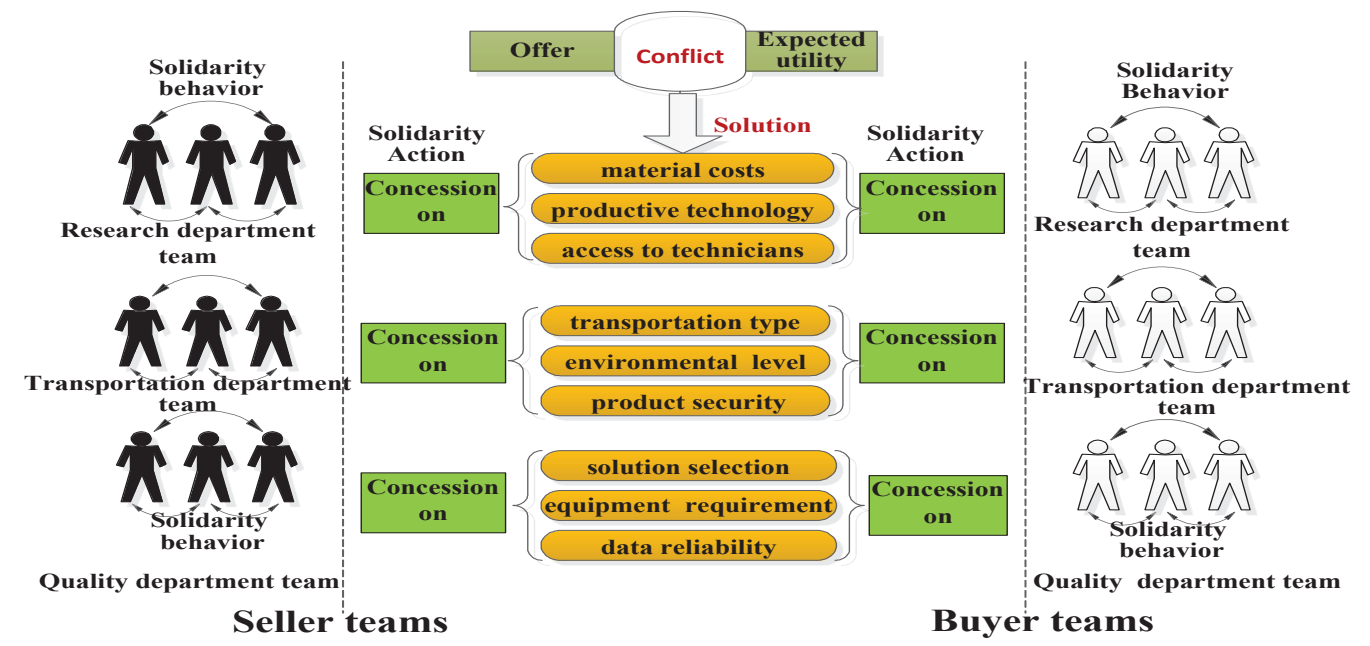

Fig. 1: Solidarity behavior in negotiation teams

Utility function. In our negotiation model, there are two negotiation parties, namely the selling party and the buying party. Each party has three negotiation department teams. For each team, the individual utility is calculated on the basis of the definitions of the weight and the normalized function in Ref. $[2,6]$. So the utility function $u_{i}(X)$ of the member $i$ is expressed as:

$$
u_{i}(X)=\sum_{j} w_{i j} * y_{j}\left(x_{j}\right)
$$

Where $i=$ member $i$, for $i=1,2, \ldots, L ; j=$ attribute $j$, for $j=1,2, \ldots, K ; L=$ number of members in each team; $K=$ number of attributes.

The parameter $x_{j}$ is the value of the attribute $j$, and $y_{j}\left(x_{j}\right)$ is the corresponding normalized function to convert the value of attribute $j$ into $[0,1]$ region. With respect to each of functional departments, the offer $X=\left\{x_{1}, x_{2}, \ldots, x_{K}\right\}$ is comprised of multiple real-valued attributes which the department team is concerned with. $w_{i j}$ is the weight given by the member $i$ to the attribute $j$, so the preference 
set of member $i$ is represented as $w_{i}=\left\{w_{i_{1}}, w_{i_{2}}, \ldots, w_{i_{K}}\right\}$. Moreover, $U=\left\{u_{1}, u_{2}, \ldots, u_{L}\right\}$ denotes the utility set of the team. And the variables $U_{b}$ denotes the set of ultimate utility for the buyer team members while $U_{s}$ denotes the set of ultimate utility for the seller team members.

The concession strategies related to solidarity factor. In order to judge whether the team member's current utility meets the interest requirement, the utility standard which is represented for his or her expected utility is used for measuring whether negotiation is worthy or not $[2,6]$. As long as the individual utility standard is varied, the acceptability of the opponent's offer may be changed, and then they may need to make concessions to form the counteroffer. In this paper, the utility standard $s_{i}(r)$ is the indicator of utility standard for the member $i$ in the $r$ th negotiation round. The set of the team members' utility standards is defined as $S=\left\{s_{1}, s_{2}, \ldots, s_{L}\right\}$.

Then, there are some criteria to decide whether to make a concession out of solidarity. In detail, the offer $X_{T \rightarrow i}$ represents the offer $X$ from the opponent team to the member $i$ and the offer $X$ is the same for all the members within the team. If the offer $X_{T \rightarrow i}$ from the opponent team provides not less benefit than utility standard in the current negotiation round, the offer will be accepted by the member $i$. On the contrary, the interest conflicts occur and the member $i$ will reject the offer $X_{T \rightarrow i}$.

The contributor makes concession on some attributes to make all the team members meet their utility standards. Then, the counteroffer is formed and is prepared for sending to the opponent team. The concession rules for the contributors making to the beneficiary are described as follows:

$$
\begin{gathered}
x_{p}=x_{p}+\left(x_{p h}-x_{p l}\right) / m, p \in D \\
x_{q}=x_{q}-\left(x_{q h}-x_{q l}\right) / m, q \in \bar{D} \\
y_{p}=\left(x_{p}-x_{p l}\right) /\left(x_{p h}-x_{p l}\right) \\
y_{q}=\left(x_{q}-x_{q l}\right) /\left(x_{q h}-x_{q l}\right)
\end{gathered}
$$

After sorting the attributes weights of the beneficiary who obtains the contribution in descending order, $D=\left\{x_{1}, x_{2}, \ldots, x_{s}\right\}$ denotes the set of attributes in the front, and the sum of these attributes weights just exceeds fifty percent. Accordingly, the set $\bar{D}=\left\{x_{s+1}, x_{s+2}, \ldots, x_{K}\right\}$ includes the other attributes. The parameter $x_{p}$ denotes the value of attribute $p$ and needs to increase in the step-size $\left(x_{p h}-x_{p l}\right) / m ; x_{p h}\left(x_{p l}\right)$ denotes the prescribed upper (lower) limit for the attribute $p$ and the parameter $m$ is a positive integer constant. Analogously, $x_{q}$ denotes the value of attribute and needs to reduce in the step-size $\left(x_{q h}-x_{q l}\right) / m$. The parameter $x_{q h}\left(x_{q l}\right)$ denotes the upper (lower) limit for the attribute $q$. In addition, the equations (4), (5) express the normalization method for the attribute $p$ and $q$ respectively. The set of the modification range of the attributes values is defined as $M R=\left\{\left[x_{1 l}, x_{1 h}\right] ;\left[x_{2 l}, x_{2 h}\right] ; \ldots ;\left[x_{k l}, x_{k h}\right]\right\}$.

Negotiation goal. The negotiation goal for each of the negotiation teams is to reach an agreement with counterparty and improve the negotiation performance as much as possible. Considering the two ways of beneficiary selection, we take the team members' average utility $\bar{u}$ as the main indicator, and view the maximum $u_{\max }$ and the minimum utility $u_{\min }$ among team members as the assisted indicators to analyze different effects on team negotiation. Moreover, if the two parties emphasis on efficiency, they may take the number of concession round $n$ into account as well.

$$
\begin{gathered}
\bar{u}=\left(\sum_{i=1}^{L} u_{i}\right) / L \\
u_{\max }=\max \left(u_{i}\right), 1 \leq i \leq L \\
u_{\min }=\min \left(u_{i}\right), 1 \leq i \leq L
\end{gathered}
$$




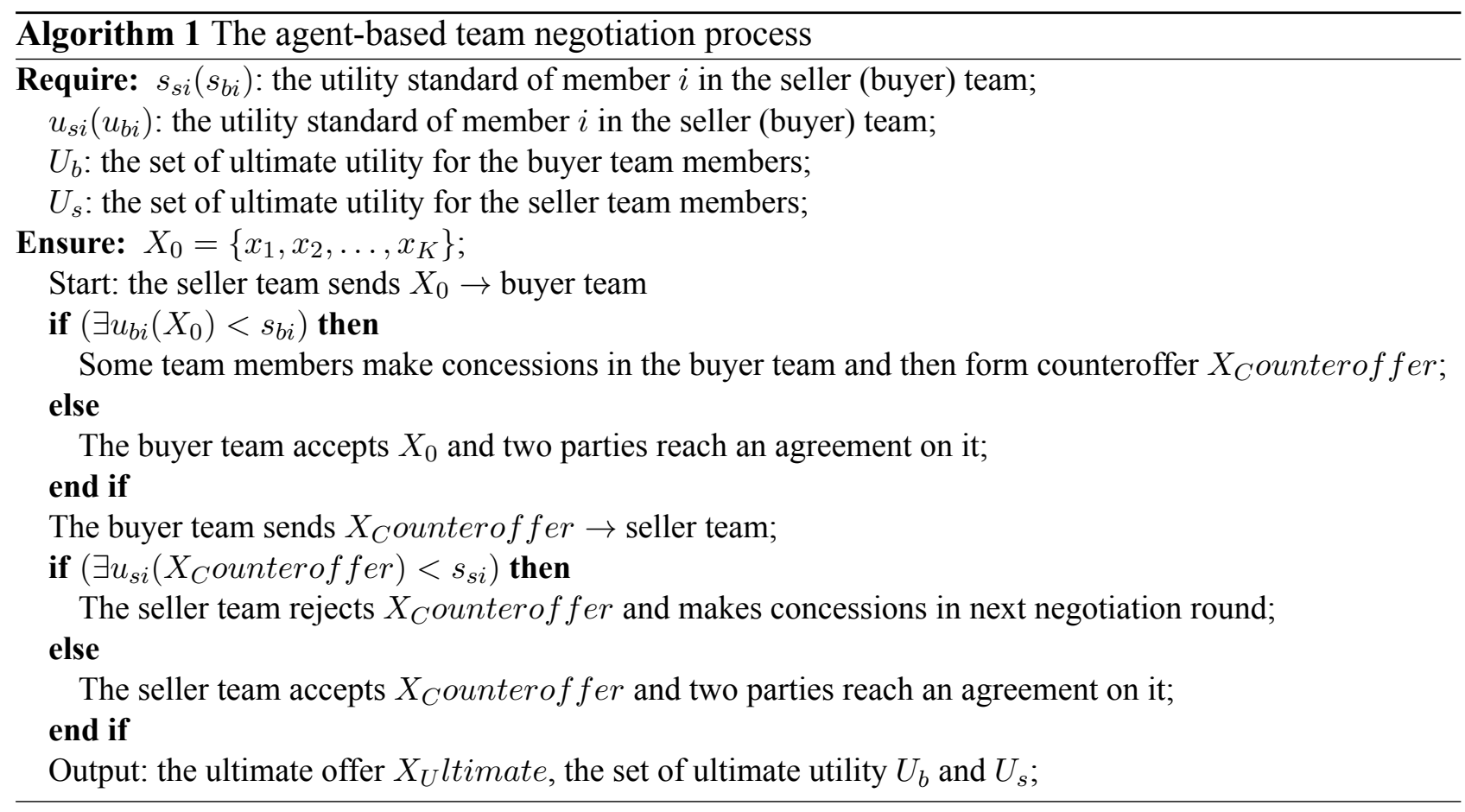

\section{Agent-based simulation approach for team negotiation}

In order to simulate the whole negotiation process under the influence of solidarity behavior, and in the meanwhile to eliminate the interest conflicts, the concession strategy has been adopted in the negotiation process. In this section, we take one of departments for instance to describe. Algorithm 1 is mainly used to implement the agent-based team negotiation process. The action pertaining to the entire team is to decide whether the offer should be accepted. If all of the agents accept the offer, the offer is accepted. Otherwise the offer is rejected. The algorithm 2 is mainly to deal with the problem when the offer is rejected by adopting the intra-team concession strategy.

Agent-based negotiation interaction process simulation. The detailed steps of the agent-based simulation approach are showed as follows:

1.The team in selling party has discussed and agreed on the initial offer for satisfying all individuals' interest requirements and then prepared to send it to the corresponding department team of buying party. The buyer team needs to propose the counteroffer in the case that not all the members accept the initial offer proposed from the seller team.

2. When the interest conflicts occur in the buyer team, some members out of solidarity select a proper beneficiary among the members and make concessions on some attributes according to the attributes preference of beneficiary. As a result, the counteroffer is formed and prepared for sending.

3.The seller team receives the counteroffer. If the offer is accepted by all the team members, the negotiation is successful. Otherwise, the seller team makes concessions in next negotiation round. The negotiation will be continued until two parties reach an agreement on the acceptable offer.The pseudocode of the algorithm for the agent-based team negotiation framework is shown as algorithm 1.

Concession strategy in the negotiation process. Under the influence of solidarity behavior, the interest conflicts can be solved by adopting the concession strategy within the team. In this section, the two ways of beneficiary selection when the contributors make concessions are described and the algorithm used to implement the concession strategy is presented. We assume that each of negotiation team relies on a trusted mediator that helps the team members to select the proper beneficiary in negotiation process. All the team members share the information with the mediator whose task involves coordination of concession process as well as communication with each team member. 


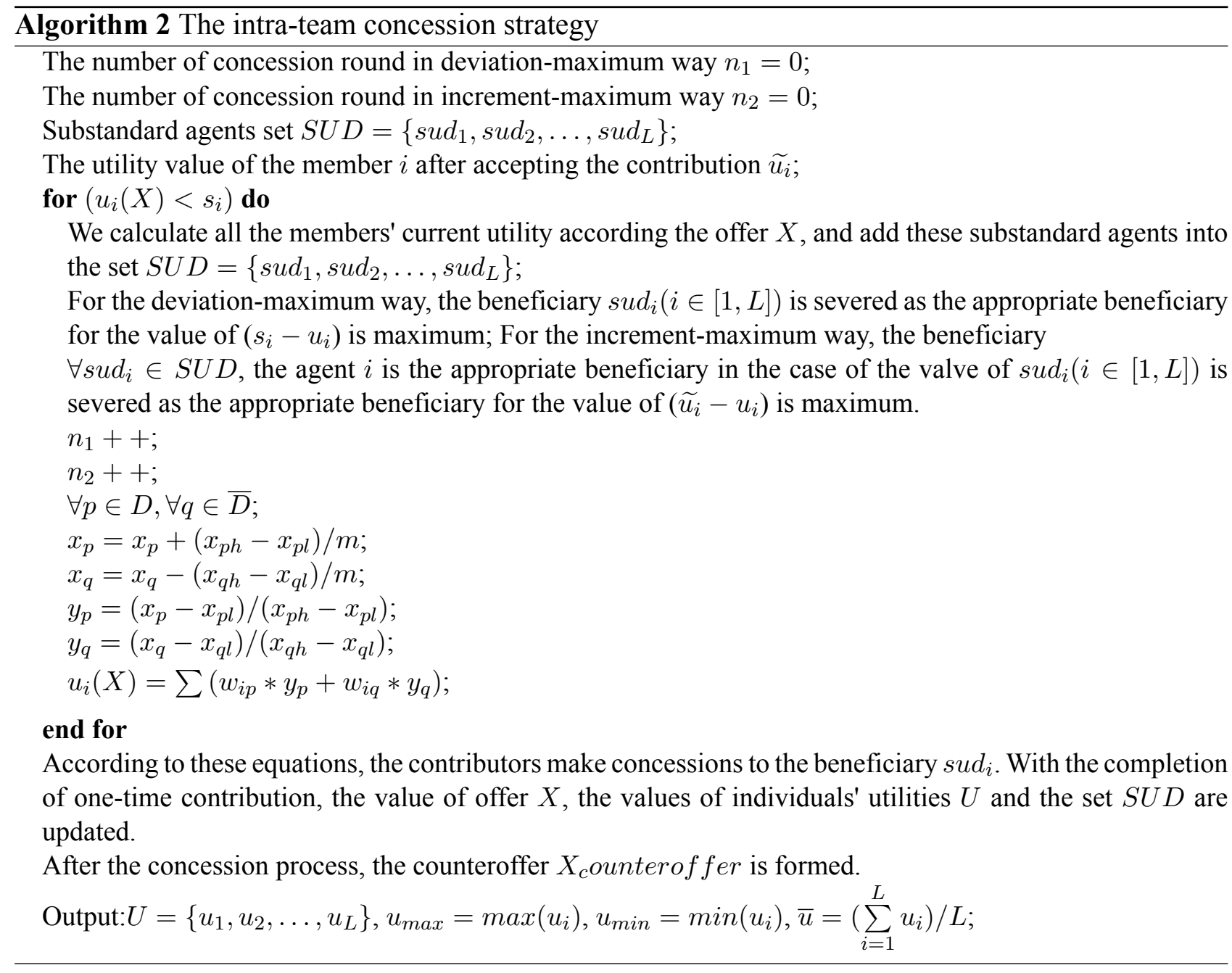

For the concession process within the team, the two different ways for selecting the beneficiary to accept the contribution is deviation-maximum way and increment-maximum way. The principle of the deviation-maximum way is that the contributors will make contributions to the team agent who is in the worst state among substandard agents, namely the current utility of the beneficiary has the maximum deviation from his or her utility standard. The principle of the increment-maximum way is that the contributors will make contributions to the team agent who is the most potential beneficiary among substandard agents, namely the beneficiary could obtain the maximum increment of the utility according to the equations (2) and (3). In addition, the concession round can also reflect the efficiency of concession process. The detailed implementation process of concession strategy within the team is shown as algorithm 2 .

\section{Experiments and results}

In order to analyze the impacts of solidarity behavior on the negotiation performance, the simulation experiments are conducted and the results are presented in this section. Firstly, according to individual utility standards, the effects of the intra-team concession strategy related to solidarity behavior are analyzed. Then, the result of the team negotiation process is presented. There are five agents in each team and each team agent concerned with five attributes. We have conducted about 1000 times for each part of experiment.

The effects of the intra-team concession strategy. The aim of the application of intra-team concession strategy is to achieve the negotiation goal. However, with the changes of the conditions such as utility standards in the negotiation environment, it seems that the two ways of beneficiary selection in- 
fluence the concession process of forming the counteroffer. As a result, it could have different effects on the negotiation outcome.

When the individual utility standard is varied slightly, the acceptability of the opponent's offer may be changed so that the negotiation outcome is affected subsequently. So it is necessary for us to do a lot of experiments to discuss the effects of the two ways of beneficiary selection in when the team agents have different utility standards. In our experiments, we increase/reduce the individual utility standard and turn it from one team agent to multiple team agents. As the input condition, the weights for each team agent are randomly generated and remain the same. In addition, the parameter related to step-size $m=40$, the modification range of the attributes values $M R=\{[2,7] ;[2,20]$; $[8$, $35] ;[3,15] ;[4,27]\}$ are necessary for clear and definite assumption. In this section the initial offer proposed by the selling party. So we take the buying party for example to analyze the effects of the two ways of beneficiary selection when the team agents have different utility standards. The set of utility standards $S=\{0.50,0.40,0.36,0.55,0.50\}$ are served as the initial condition for the buying party and we modify the utility standard based on the initial set. The number of concession rounds $n$, the maximum utility $u_{\max }$, the minimum utility $u_{\min }$ and the average utility of all team agents $\bar{u}$ are served as the performance indicators in team negotiation.

In our experiments, in order to sum them up for obtaining regularity cognition to apply for negotiation further, we use the statistical technique to analyze data from a great deal of trials. We have selected 25 groups for instance and then divided these groups into several parts like (a)-(f) according to the feature of number of concession rounds and the utility values in Tables 1 . The underline symbol is just employed for comparing the corresponding value of utility standard with that in the set of utility standards $S$.

From the Table 1, the results of part (a) indicate that the concession process just need one round or two rounds. The reason of this case is that the reasonable relocation of utility standards may contribute to efficient negotiation. Moreover, whether increasing or decreasing corresponding utility standards, the results of part (b) are same as that in the initial condition. The main reason is that despite utility standards are varied, the contributors are the same in each corresponding concession round in these situations. Otherwise, only if the varied utility standard cause the team agent can not meet his or her interest requirement any more, the negotiation outcome is affected. In addition in part (c), the relative high standards make some beneficiaries can hardly meet their interest requirements after accepting the contribution in the increment-maximum way after concession more than once. Because this situation is impractical, we do not record it and mark it with horizontal line. The double arrow symbols in the part (d) shown in Table 1 represent that the attributes values exceed the modification range and their utility values are not meaningful in these cases. These unexpected situations are mainly because some preferred attributes for different beneficiaries are overlap so that the monotonous variation occurs, and the relative high standards also make some beneficiaries can hardly meet their interest requirements after accepting the contribution.

We can also observe that the increment-maximum way always has advantage in the final benefit for the team agents while the deviation-maximum way has the advantage in the efficiency for the less concession rounds. As the part (e) has shown, the average utility and the maximum utility in the increment-maximum way may not be less than that in the deviation-maximum way. The main difference resides in the fact that the different principles of beneficiary selection cause different negotiation processes and outcomes: the deviation-maximum way places emphasis on the contribution to the weakest whereas the increment-maximum way focuses on the large dominant effect on the beneficiary. Besides, the reason why the results of part (f) indicate the same outcome for two ways is that the varied utility stands have effects on performance but not enough to cause difference in beneficiary selection.

In general, experimental results show that increasing team agents' utility standards on the basis of the initial condition to some extent will lead to longer concession process whereas reducing their utility standards contributes to shorter concession process. Meanwhile, the maximum utility and the average 
Table 1: The table depicts the comparison of two ways of beneficiary selection when buying party needs to propose the counteroffer. Results show the number of concession rounds and the utility values.

\begin{tabular}{|c|c|c|c|c|c|c|c|c|c|}
\hline \multirow{2}{*}{ group } & \multirow{2}{*}{$\begin{array}{l}\text { The set of the team members' } \\
\text { utility standards }\end{array}$} & \multicolumn{4}{|c|}{ The deviation-maximum way } & \multicolumn{4}{|c|}{ The increment-maximum way } \\
\hline & & $n_{1}$ & $u_{\max 1}$ & $u_{\min 1}$ & $\overline{u_{1}}$ & $n_{2}$ & $u_{\max 2}$ & $u_{\min 2}$ & $\overline{u_{2}}$ \\
\hline initial & $\{0.500,0.400,0.360,0.550,0.500\}$ & 7 & 0.5556 & 0.5058 & 0.5349 & 7 & 0.5556 & 0.5058 & 0.5349 \\
\hline \multirow{2}{*}{$(a)$} & $\{0.500,0.400,0.348,0.520,0.500\}$ & 2 & 0.5446 & 0.5121 & 0.5282 & 2 & 0.5446 & 0.5121 & 0.5282 \\
\hline & $\{0.500,0.400, \overline{0.500,0.500}, 0.550\}$ & 1 & 0.5502 & 0.5351 & 0.5271 & 1 & 0.5502 & 0.5351 & 0.5271 \\
\hline \multirow{5}{*}{ (b) } & $\{0.500, \underline{0.380}, 0.360,0.550,0.500\}$ & 7 & 0.5556 & 0.5058 & 0.5349 & 7 & 0.5556 & 0.5058 & 0.5349 \\
\hline & $\{0.500,0.440,0.360,0.550,0.500\}$ & 7 & 0.5556 & 0.5058 & 0.5349 & 7 & 0.5556 & 0.5058 & 0.5349 \\
\hline & $\{0.500, \underline{0.500}, 0.360,0.550,0.500\}$ & 7 & 0.5556 & 0.5058 & 0.5349 & 7 & 0.5556 & 0.5058 & 0.5349 \\
\hline & $\{0.500,0.300,0.100,0.550,0.500\}$ & 7 & 0.5556 & 0.5058 & 0.5349 & 7 & 0.5556 & 0.5058 & 0.5349 \\
\hline & $\{0.500, \overline{0.500,0.400}, 0.550,0.500\}$ & 7 & 0.5556 & 0.5058 & 0.5349 & 7 & 0.5556 & 0.5058 & 0.5349 \\
\hline \multirow{3}{*}{ (c) } & $\{0.500, \underline{0.550}, 0.360,0.550,0.500\}$ & 8 & 0.5736 & 0.4987 & 0.5367 & - & - & - & - \\
\hline & $\{0.500,0.400,0.360,0.550, \underline{0.570}\}$ & 8 & 0.5736 & 0.4987 & 0.5367 & - & - & - & - \\
\hline & $\{0.500,0.400,0.360,0.563,0.569\}$ & 10 & 0.5780 & 0.4886 & 0.5394 & - & - & - & - \\
\hline$(d)$ & $\{0.500,0.540,0.500,0.550,0.500\}$ & 9 & 0.5653 & 0.5098 & 0.5397 & 15 & $\leftrightarrow$ & $\leftrightarrow$ & $\leftrightarrow$ \\
\hline \multirow{7}{*}{$(e)$} & $\{0.500, \underline{0.530}, 0.360,0.550,0.500\}$ & 7 & 0.5556 & 0.5058 & 0.5349 & 8 & 0.5736 & 0.4987 & 0.5367 \\
\hline & $\{0.500, \underline{0.524}, 0.360,0.550,0.500\}$ & 7 & 0.5556 & 0.5058 & 0.5349 & 8 & 0.5736 & 0.4987 & 0.5367 \\
\hline & $\{0.500,0.400,0.360,0.550, \underline{0.560}\}$ & 8 & 0.5657 & 0.4997 & 0.5365 & 8 & 0.5736 & 0.4987 & 0.5367 \\
\hline & $\{0.500,0.520,0.500,0.550,0.500\}$ & 7 & 0.5556 & 0.5058 & 0.5349 & 9 & 0.5732 & 0.5056 & 0.5399 \\
\hline & $\{0.500, \overline{0.400,0.360}, 0.560,0.550\}$ & 9 & 0.5637 & 0.4957 & 0.5376 & 9 & 0.5679 & 0.4947 & 0.5378 \\
\hline & $\{0.500,0.400,0.360, \overline{0.560,0.560}\}$ & 9 & 0.5637 & 0.4957 & 0.5376 & 9 & 0.5758 & 0.4937 & 0.5381 \\
\hline & $\{0.500,0.440,0.380, \overline{0.540,0.560}\}$ & 6 & 0.5613 & 0.5098 & 0.5338 & 6 & 0.5692 & 0.5039 & 0.5341 \\
\hline \multirow{6}{*}{$(f)$} & $\{0.500,0.400,0.360, \underline{0.569}, 0.500\}$ & 10 & 0.5697 & 0.4907 & 0.5390 & 10 & 0.5697 & 0.4907 & 0.5390 \\
\hline & $\{0.500,0.400,0.360, \underline{0.540}, 0.500\}$ & 6 & 0.5534 & 0.5109 & 0.5336 & 6 & 0.5534 & 0.5109 & 0.5336 \\
\hline & $\{0.500,0.400,0.360, \underline{0.530}, 0.500\}$ & 3 & 0.5490 & 0.5200 & 0.5309 & 3 & 0.5490 & 0.5200 & 0.5309 \\
\hline & $\{0.500,0.400,0.530, \overline{0.550}, 0.500\}$ & 10 & 0.5545 & 0.5359 & 0.5445 & 10 & 0.5545 & 0.5359 & 0.5445 \\
\hline & $\{0.500,0.400,0.360, \underline{0.562}, 0.500\}$ & 9 & 0.5637 & 0.4957 & 0.5376 & 9 & 0.5637 & 0.4957 & 0.5376 \\
\hline & $\{0.500,0.400,0.360,0.540,0.430\}$ & 6 & 0.5534 & 0.5109 & 0.5336 & 6 & 0.5534 & 0.5109 & 0.5336 \\
\hline
\end{tabular}

utility of the team increase, and even the minimum utility increases frequently in the case of the relative high utility standards. It means that the relative high utility standards can promote the competent team agents to make concessions. In addition, the experimental data show that the negotiation outcome is easier to be affected when more team agents modify their utility standards. One interpretation may be that, leaving more room to increase the utility for meeting all the individuals' utility standards is favorable to enhance the overall benefit of the team. However, in these cases, more concession rounds may be needed to form the accepted counteroffer.

In summary, it is can be found that even though both ways are out of the solidarity factor, and their aims are to meet the team agents' interest requirements, the effects on the negotiation performance are not the same. In any cases, the team would benefit more in the increment-maximum way. In addition, the deviation-maximum way is efficient with the less concession rounds, and it is more practical for 
not appearing lengthy concession process or not exceeding the modification range of the attributes values.

The results of the whole negotiation process. During the negotiation process, the negotiation teams adopt the heuristic rule to advance the negotiation process and make decisions on the concession strategy under the influence of solidarity factor. Hundreds of experiments are conducted to verify the positive significance of solidarity behavior in the agent-based team negotiation. In these experiments, one of department teams that is randomly generated and represents the selling party to negotiate with corresponding department team that represents the buying party in order to complement the negotiation sub-task. Each team is consisted of five team agents and team agents concerned with the same five attributes within the team. The weight preferences and the initial utility standards for two teams are also randomly generated. Because different concession situations take place in each of the experiments, the following negotiation process is taken as an example to illustrate how to make use of the solidarity factor to make concessions.

The parameters are initialized as follows: the initial offer proposed by the selling party, the stepsize and the modification range of the attributes are same to the initial input data defined in the former experiment. In addition, the weight preferences and the utility standards for each team are shown in Table 2. The results of the whole negotiation process are shown in the Table 3.

Table 2: The table indicates the weight preferences and the utility standards for the negotiation teams.

\begin{aligned} &$S_{s}=\{0.4910,0.4700,0.5100,0.46500 .4420\} \\ &$\hline$\omega_{s 1}=\{0.2003,0.2376,0.1900,0.1480,0.2240\} \\ & \omega_{s 2}=\{0.2078,0.2179,0.2040,0.3033,0.0670\} \\ & \omega_{s 3}=\{0.3342,0.1113,0.0563,0.2861,0.2121\} \\ & \omega_{s 4}=\{0.1580,0.2280,0.2653,0.1206,0.2280\} \\ & \omega_{s 5}=\{0.1406,0.2843,0.2813,0.0866,0.2072\} \\ &$\hline$S_{b}=\{0.4800,0.4700,0.4980,0.5220,0.5100\} \\ &$\hline$\omega_{b 1}=\{0.2429,0.3407,0.2899,0.0153,0.1112\} \\ & \omega_{b 2}=\{0.1518,0.1232,0.1409,0.3435,0.2406\} \\ & \omega_{b 3}=\{0.2408,0.3414,0.0323,0.0536,0.3319\} \\ & \omega_{b 4}=\{0.2179,0.2420,0.0826,0.2155,0.2419\} \\ & \omega_{b 5}=\{0.1160,0.4027,0.0200,0.0734,0.3879\} \\ &$\hline\end{aligned}

To begin with, the seller team proposes the initial offer $X_{0}=\{5,8,15,12,18\}$ to the buyer team. Then, some members in the buyer team make concessions out of solidarity because not all the team members' utility standards can be met. Considering the two ways of beneficiary selection, the process in increment-maximum way is slightly longer and the average utility is higher than that in deviationmaximum way. In order to obtain the higher benefits for the buyer team, the increment-maximum way is selected and the offer $X_{c}$ ounterof fer $=\{4.500,13.400,15.000,8.400,18.000\}$ is sent to the opponent team. As a result, all the team members in seller team accept the counteroffer for meeting their interest requirement and reach an agreement efficiently. Otherwise, the seller team rejects opponent's counteroffer and needs to make concessions in another negotiation round.

\section{Conclusions and future work}

At present, the effectiveness of team negotiation in various negotiation environments has deserved extensive attention. The solidarity behavior, as one of the important team characteristics, may influence the negotiation process and outcome. In this paper, the problem of how solidarity behavior affects the negotiation process and improves the negotiation performance is considered. Team negotiation 
Table 3: The table records the whole negotiation process and shows the negotiation outcome.

process The deviation-maximum way The increment-maximum way

initial conditions: $X_{0}=\{5,8,15,12,18\} ; m=40 ; M R=\{[2,7] ;[2,20] ;[8,35] ;[3,15] ;[4,27]\}$

the initial offer $X_{0}$ proposed from the seller team is sent to the buyer team

\begin{tabular}{|c|c|c|c|c|c|c|c|c|}
\hline \multirow{2}{*}{$\begin{array}{l}X_{0} \rightarrow \text { buyer } \\
\text { team }\end{array}$} & $n_{1}$ & $\overline{u_{1}}$ & $u_{\min 1}$ & $u_{\max 1}$ & $n_{2}$ & $\overline{u_{2}}$ & $u_{\min 2}$ & $u_{\max 2}$ \\
\hline & 11 & 0.5303 & 0.4894 & 0.5728 & 12 & 0.5330 & 0.4870 & 0.5874 \\
\hline$X_{\text {counteroffer }}$ & $\{4.6$ & $25,12$. & $50,15.6$ & $.700,17.425\}$ & $\{4.5$ & $00,13.4$ & $400,15.0$ & $400,18.000\}$ \\
\hline
\end{tabular}

$\mathrm{t}$ he increment-maximum way is selected and the counteroffer $X_{\text {counterof fer }}$ is sent to the seller team

$$
\begin{gathered}
S_{s}=\{0.4910,0.4700,0.5100,0.4650,0.4420\} \\
U_{s}\left(X_{\text {counteroffer }}\right)=\{0.5028,0.4721,0.5100,0.4852,0.4884\} \\
u_{s i}>s_{s i}
\end{gathered}
$$

Evaluation: two parties reach an agreement on the offer $X_{\text {counteroffer }}$ and the team negotiation ends

strategies and protocols related to solidarity behavior are modeled, and the agent-based simulation approach is introduced to construct the simulated team negotiation environment. Considering the individual utility standards, the effects of the different ways of beneficiary selection on the intra-team concession strategy are analyzed. Then the effectiveness of the whole team negotiation is verified as well. As shown in the experiments of different utility standards, the increasing of utility standards for individuals will lead to longer concession process but more benefits. In the meanwhile, the team would benefit more in the increment-maximum way whereas the deviation-maximum way is practical and efficient for the less concession rounds.

In the future work, we will consider other team characteristics in the team negotiation environments. For instance, the egocentric behavior of team members, preference weights and power distance within the team will have great impact on the decision-making process. The participation of new members or team reorganization will make the team negotiation environment dynamic, which also have influences on the negotiation process. In addition, the coalition formation for sub-groups to share responsibility are also worthy of our exploration.

\section{Acknowledgements}

This work was supported by National Natural Science Foundation of China (Grand No. 71271094).

\section{References}

[1] S. T. Yuan and Y. H. Lin. Credit based group negotiation for aggregate sell/buy in e-markets. Electronic Commerce Research and Applications, vol. 3, pp. 74-94, 2004.

[2] V. Sanchez-Anguix, T. L. Dai, Z. Semnani-Azad, K. Sycara and V. Botti. Modeling power distance and individualism/collectivism in negotiation team dynamics. In Proc. 45th Int. Conf. System Sciences, 2012.

[3] R. Wilken, F. Jacob and N. Prime. The ambiguous role of cultural moderators in intercultural business negotiations. International Business Review, vol. 22, no. 4, pp. 736-753, Aug. 2013.

[4] T. Vuorela. Laughing matters: A case study of humor in multicultural business negotiations. Negotiation Journal, vol. 21, no. 1, pp. 105-130, Jan. 2005.

[5] V. Sanchez-Anguix, V. Julian, V. Botti and A .Garc"aa-Fornes. Reaching Unanimous Agreements Within AgentBased Negotiation Teams With Linear and Monotonic Utility Functions. IEEE Trans. Syst., Man, Cybern. B, Cybern., vol. 42, no. 3, pp. 778-92. Jun. 2012. 
[6] N. Halevy. Team negotiation: social, epistemic, economic, and psychological consequences of subgroup conflict. Pers. Soc. Psychol. Bull, vol. 34, no. 12, pp. 1687-1702, Dec. 2008.

[7] L. Crump. For the Sake of the Team: Unity and Disunity in a Multiparty Major League Baseball Negotiation. Negotiation Journal, vol.21, no. 3, pp. 317-342, July 2005.

[8] M. Bacharach. Interactive team reasoning: A contribution to the theory of co-coperation. Research in Economics, vol. 53, pp.117-147, 1999.

[9] H. Suryotrisongko and Y. Ishida. Emergence of Cooperation as the Impact of Evacuee's Solidarity. 2011 IEEE Int. Symposium Safety, Security and Rescue Robotics, Nov. 2011, pp.265-271.

[10] V. Sanchez-Anguix. Negotiation Teams in Multiagent Systems. In proc. 10th Int. Conf. on Autonomous Agents and Multiagent Systems, vol. 3, pp. 1357-1358, May 2011.

[11] M Ayé, F Champagne, AP Contandriopoulos. Economic role of solidarity and social capital in accessing modern health care services in the Ivory Coast. Social Science and Medicine, vol. 55, no. 11, pp. 1929-1946, Dec. 2002.

[12] S. Reinhard and O. Axel. An experimental solidarity game. Economic Behavior and Organization, vol. 34, no. 4, pp. 517-539, Mar. 1998.

[13] J. C. Coxa, D. Friedmanb and S. Gjerstadc. A tractable model of reciprocity and fairness. Games and Economic Behavior, vol.59, no. 1, pp.17-45, Apr., 2007.

[14] Luo He, Yang Shanlin, Hu Xiaoxuan. The Framework for Multi Agent Concurrent Negotiation. Pacific-Asia Conference on Web Mining and Web-based Application- WMWA, 2009.

[15] V. Sanchez-Anguix, V. Julian, V. Botti and A .Garc“aa-Fornes. Analyzing Intra-Team Strategies for Agent-Based Negotiation Teams. In proc. 10th Int. Conf. on Autonomous Agents and Multiagent Systems, May 2011, vol. 3, pp. 929-936.

[16] C. C. Huang, W.Y. Liang, Y.H. Lai and Y.C. Lin. The agent-based negotiation process for B2C e-commerce. Expert Systems with Applications, vol. 37, no. 1, pp. 348-359, Jan. 2010.

[17] N. M. Sbrockey, S. Z. Sun and G. S. Tompa. Low cost production of InGaN for next-generation photovoltaic devices. Structured Materials Industries, Inc., Mar. 2012.

[18] G. L. Henriksen, K. Amine and J. Liu. Materials cost evaluation report for high-power Li-ion batteries. Freedom CAR and Vehicle Technologies Office, Jan. 2003. [Online]. Available: http://www.doe.gov/bridge.

[19] David E. Dodds, M. Shafique and B. Celaya. TDR and FDR identification of bad splices in telephone cables. In proc. Canadian conf. Electrical and Computer Engineering, 2006, pp. 838-841.

[20] Andrew Cox, Fynnwin Prager, Adam Rose. Transportation security and the role of resilience: A foundation for operational metrics. Transport Policy, vol. 18, no. 2, pp. 307-317, Mar. 2011.

[21] V. G. Agelidis, A. I. Balouktsis and C. Cossar. On attaining the multiple solutions of selective harmonic elimination PWM three-level waveforms through function minimization. IEEE Transactions on Industrial Electronics, vol. 55, no. 3, pp. 996-1004, 2008.

[22] E. Laine, K. Ruhmer, L. Belanger, M. Turgeon, E. Perfecto, H. Longworth and D. Hawken. C4NP - lead free flip chip solder bumping manufacturing and reliability data. in proc. 7th Int. conf. Electronic Packaging Technology, 2006.

[23] Elmar M. Merkle, Jonathan S. Lewin, Ram Liebenthal and Christine H. Lorenz. The interventional MR imaging suite: Magnet designs and equipment requirements. Magnetic Resonance Imaging Clinics of North America, vol. 13, no. 3, pp. 401-413, 2005. 